\title{
PARASITIC INFECTIONS AMONG CHILDREN OF SQUATTER COMMUNITY IN DHARAN MUNICIPALITY, SUNSARI, NEPAL
}

\author{
R. Chongbang ${ }^{1}$, P. Dongol ${ }^{1}$, A. Chakrawarti ${ }^{1}$ and H. Khanal ${ }^{2 *}$ \\ ${ }^{1}$ Department of Microbiology, Sunsari Technical College, Dharan, Sunsari, Nepal \\ ${ }^{2}$ Department of Microbiology, Central Campus of Technology, Hattisar, Dharan, Nepal
}

*Corresponding Author email: khanal.hemanta@gmail.com

\begin{abstract}
Background and Objective: Children of squatter community are more prone to many infections and epidemiological studies provide to develop suitable preventive plans. Thus, the main objective of the present study was to determine the prevalence of parasitic infections among children of Squatter Community of Dharan Municipality. Methodology: Altogether 184 stool samples were collected from June 2014 to January 2015. The samples were examined using direct microscopy by saline wet mount technique in the microbiology laboratory of Sunsari Technical College, Dharan. Results: The overall prevalence of intestinal parasites was found to be $41.4 \%$ with male children more infected (45.8\%) than female children (37.5\%). Children between 4-8 years of age were most infected (48.1\%). Among 4 species of parasites detected Ascaris lumbricoides $(18.1 \%)$ was the commonest helminths and Giardia lamblia $(74.02 \%)$ was the commonest protozoa. Positive rate was higher in Dalits $(59.7 \%, 43 / 72)$ and the least in Tibeto-Burman $(27.1 \%, 22 / 81)(\mathrm{p}<0.05)$ ethnic groups.52.5\% of children not using water and $33.6 \%$ of children using bucket water at toilet after defecation were infected. Children using soap for hand washing after defecation were less infected $(32.02 \%)$ than other children $(55.1 \%)$. Children taking the anti-parasitic drug in last six months had significantly low positive rate (9.3\%) than others $(51.7 \%)(\mathrm{p}<0.05)$. Conclusion: High prevalence of parasitic infection was observed among children in Squatter community of Dharan Municipality. Thus, health education along with infection management actions and the awareness programs for sanitation improvements are required to reduce the parasitosis.
\end{abstract}

Keywords: Children; Parasitic infection; Prevalence; Dharan Municipality; Squatter Community

\section{Introduction}

It has been estimated by WHO that about 3.5 billion people are infected and some 450 million people become ill due to Intestinal helminths and protozoan parasites worldwide with the children being affected the most (WHO, 2013). Intestinal parasitic infections are most prevalent in children and is a major public health problem in Nepal (Chandrashekhar et al., 2005). According to the latest estimated report, more than 880 million children are in need of treatment for parasitic infections (WHO, 2014). Parasitic infection usually consorts with scrawny body development, weak nutritional status and, poor education in patients, especially children. In fact, the pathogenesis, morbidity and mortality of the intestinal parasites differ from species to species and also influenced by social, geographical, economical and inhabitant customs and poor personal hygiene of people (Latham, 1997). The most common helminths infecting human is Ascaris lumbricoides while Hymenolepsis nana is the cestodes globally prevalent whereas Giardia lamblia, causing giardiasis is the most common protozoan parasite infecting humans worldwide (Boggish, 2013).

Squatter refers to the people living without land ownership so they do not have proper sanitary and waste disposal system. They are socio-economically very backward and are most prone to be infected with intestinal parasites (Nepal Survey Division, 2000). People living in Squatter Community is unable to access primary health care, basic education and safe drinking water due to poverty (IFAD, 2010). Moreover, poor people of developing countries live in very congested settlements mostly of temporary in nature. Therefore, it is likely to have a higher rate of intestinal parasitic infection particularly among people and mostly in children of developing countries (Mathers, 2008). Thus, this study was conducted to determine the prevalence of intestinal parasitosis among the children of Squatter Community in Dharan Municipality.

\section{Materials and Methods}

Altogether 184 fecal samples were detected from children of age 1 to16 years (males: 96; females: 88) of a Squatter 
Community in Dharan Municipality. Children were provided a clean, dry, screw-capped plastic container visiting each of household in the community. Instruction regarding fecal sample collection was given during sample container distribution. The collected stool samples were transported to the microbiology laboratory of Sunsari Technical College, Dharan. After visible examination for the presence of adult worms in stool, all the preparation was examined under direct microscopy using wet mount technique and concentration method using $10 \%$ formal ether. All positive findings were noted. Informed consent from the parents of the children was taken and a set of questionnaires were provided for non-experimental data collections regarding sanitary information and predisposing factors of parasitic infections was determined. Different statistical tools were applied for analysis of results.

\section{Results}

The overall prevalence of intestinal parasites was found to be $(42.93 \%)$. Males were marginally more infected $(47.91 \%)$ than female $(37.5 \%)$. The ratio of infections below 8 years was almost equal to $48 \%$ and children of 12 years above were less infected (19.35\%).

Table 1: Gender wise prevalence of Parasitosis

\begin{tabular}{|l|l|l|l|l|}
\hline Sex & Total & Parasitosis & \% & p-value \\
\hline Male & 96 & 46 & 47.91 & \\
\cline { 1 - 2 } $\begin{array}{l}\text { Fema } \\
\text { le }\end{array}$ & 88 & 33 & 37.5 & \multirow{2}{*}{$<0.05$} \\
\cline { 1 - 2 } Total & 184 & 79 & 42.93 & \\
\hline
\end{tabular}

Nearly half of the children were infected below 12 years of age group and less prevalence (19.35\%) was observed among 12 to 16 years of age group (Table 2).

Only four intestinal parasites were observed with the highest prevalence of only one species of protozoan Giardia lamblia $(73.41 \%)$ and three helminths are Ascaris lumbricoides (18.98\%), hookworm (6.32\%), Hymenolepsis nana (1.26\%) among the infected population (Table 3 ).
Table 2: Frequency of Parasitosis according to age group

\begin{tabular}{|l|l|l|l|l|}
\hline S.N. & $\begin{array}{l}\text { Age } \\
\text { Groups }\end{array}$ & $\begin{array}{l}\text { Total } \\
\text { Population }\end{array}$ & Pos n & Prevalence \\
\hline $\mathbf{1}$ & $<4$ & 50 & 24 & $48 \%$ \\
\hline $\mathbf{2}$ & $4-8$ & 54 & 26 & $48.14 \%$ \\
\hline $\mathbf{3}$ & $8-12$ & 49 & 23 & $46.93 \%$ \\
\hline $\mathbf{4}$ & $12-16$ & 31 & 6 & $19.35 \%$ \\
\hline Total & & 184 & 79 & $42.93 \%$ \\
\hline
\end{tabular}

Table 3: Types and frequency of parasite detected

\begin{tabular}{lll}
\hline Parasites & Total positive no. & \% \\
\hline Protozoan & & \\
G. lamblia & 58 & 73.41 \\
Helminths & & \\
A. lumbricoides & 15 & 18.98 \\
Hookworm & 5 & 6.32 \\
H. nana & 1 & 1.26 \\
Total parasites & $\mathbf{7 9}$ & $\mathbf{1 0 0}$ \\
\hline
\end{tabular}

Ethnically, Dalit children were highly infected (63.88\%) than Indo-Aryan $(38.7 \%)$ and Tibeto-Burman with the prevalence of $25.92 \%$ ( $p>0.05)$ (Table 4).

Statistically significance parasitic infections were detected from $55 \%$ (44/80) of those children who do not use water after defecation and $33.6 \%(35 / 104)$ prevalence on hand washer children were detected positive (Table 5).

One-third of children who had their water in their toilet were found to be infected with the prevalence rate of $33.65 \%$ $(35 / 104)$ and more than half of children are found to be infected with $55 \%$ (44/80) prevalence rate (Table 6). Similarly, those children who use soap water after defecation were infected with one-third rate of $32.07 \%$ (34/106) and more than half of children who did not use soap water were infected 57.69\% (45/78) (Table 7).

Table 4: Parasitosis in different ethnic groups

\begin{tabular}{|l|l|l|l|l|l|l|}
\hline \multirow{2}{*}{ Ethnic group } & \multirow{2}{*}{ Total population } & \multicolumn{4}{|c|}{ Positive } & \multirow{2}{*}{ p-value } \\
\cline { 3 - 7 } & & Male & Female & Total & $\%$ Prevalence \\
\hline Dalit & 72 & 24 & 22 & 46 & $46 / 72(63.88)$ \\
\hline Tibeto-Burmans & 81 & 14 & 7 & 21 & $21 / 81(25.92)$ & $<0.05$ \\
\hline Indo-aryan & 31 & 8 & 4 & 12 & $12 / 31(38.7)$ & $79 / 184(42.93)$ \\
\hline Total & 184 & 46 & 33 & 79 & 79 \\
\hline
\end{tabular}

Table 5: Parasitosis according to hand washing practice

\begin{tabular}{|l|l|l|l|l|}
\hline $\begin{array}{l}\text { Parasitosis and hand washing } \\
\text { practice }\end{array}$ & $\begin{array}{l}\text { Hand washers after } \\
\text { defecation }\end{array}$ & $\begin{array}{l}\text { Hand not washers after } \\
\text { defecation }\end{array}$ & Total & p-value \\
\hline Parasitosis Detected & 35 & 44 & 79 & \\
\hline Parasitosis not Detected & 69 & 36 & 105 & $<0.05$ \\
\hline Total & 104 & 80 & 184 & \\
\hline
\end{tabular}


R. Chongbang et al. (2016) Int J Appl Sci Biotechnol, Vol 4(2): 203-206

Table 6: Parasitosis according to water availability in toilet

\begin{tabular}{|c|c|c|c|c|}
\hline $\begin{array}{l}\text { Availability of } \\
\text { water in toilet }\end{array}$ & Total n & Pos n & $\%$ & p-value \\
\hline Yes & 104 & 35 & 33.65 & \multirow{3}{*}{$<0.05$} \\
\hline No & 80 & 44 & 55 & \\
\hline Total & 184 & 79 & 42.93 & \\
\hline
\end{tabular}

Table 7: Parasitosis on children who use soap after defecation

\begin{tabular}{|l|l|l|l|l|}
\hline $\begin{array}{l}\text { Use of soap } \\
\text { water }\end{array}$ & Total n & Pos n & $\mathbf{\%}$ & p-value \\
\cline { 1 - 4 } Yes & 106 & 34 & 32.07 & \multirow{2}{*}{$<0.05$} \\
\cline { 1 - 4 } No & 78 & 45 & 57.69 & \\
\hline Total & 184 & 79 & 42.93 & \\
\hline
\end{tabular}

Only $9.3 \%$ (4/43) of children who had taken the anthelminthic drugs in past six months were observed to be infected but more than half of the children were infected with the prevalence rate of 53.19\% (75/141) among children who did not take the similar drug in past six months (Table 8).

Table 8: Prevalence of parasitic infection in relation to antiparasitic drug intake in the past six months

\begin{tabular}{|l|l|l|l|l|}
\hline $\begin{array}{l}\text { Anti- } \\
\text { helminthic } \\
\text { drug }\end{array}$ & Total n & Pos n & $\boldsymbol{\%}$ & p-value \\
\hline Yes & 43 & 4 & 9.3 & \multirow{2}{*}{0.00} \\
\hline No & 141 & 75 & 53.19 & \\
\hline Total & 184 & 79 & 42.93 & \\
\hline
\end{tabular}

\section{Discussion}

Sanitation and proper waste disposal are a major problem in squatter community because of poor socio-economic conditions. They share a house with domesticated animals and pets which are a good indicator of the poverty and poor hygienic condition of the household. Although more than one-third of the children were infected in this study with any one type of parasites, the result is found to be less prevalent on parasitic infection than on a research was done by Magar et al., 2011 at Kathmandu valley which was $43.3 \%$ and higher than observed by Khanal et al., on 2011 at Kathmandu (17.6\%) and Chandrashekhar et al., at Kaski (21.3\%) on 2005 and Gyawali et al., at 2009 at Dharan $(22.5 \%)$. This investigation showed the report of the very high positive rate of intestinal parasitic infections according to previous research among children elsewhere in the country (Mukhiya et al., 2012; Jaiswal et al., 2013). In Nepal highest prevalence published till now is $81.94 \%$ on 2003 among healthy children of Lalitpur district by Shrestha and the overall prevalence of our study was less than this report.

A marginally higher positive rate of infection among boys as compared to girls was observed in this study which might be due to more outdoor activities of male children. This result agrees with the data of study done by Shrestha et al., on 2012. Helminthic infections were less prevalent as compared to the protozoal infections and this result was similar to other studies were done in Dharan and Kathmandu (Gyawali et al., 2009; Pradhan et al., 2014). The Periodic campaign of anti-helminthic drug administration to the children and nationwide bi-annual integrated deworming as well as Vitamin A supplementation could possibly explain the lower prevalence of helminthic infections seen in this study (DoHS, 2010/11). Giardia lamblia was the only and the most prevalent $(73.41 \%)$ protozoan among intestinal parasites. The finding was consistent with other reports from Nepal (Pooja et al., 2014, Gyawali et al., 2009). Unhealthy lifestyle, poor hygiene and lack of potable water might be the cause of high frequency of G. lamblia among squatter community children. Furthermore, contamination of drinking water in Nepal by fecal matter and the resistance of $G$. lamblia cyst to the normal level of chlorination of drinking water aid in parasitic infection in such areas (Magar et al., 2011). The result of the most prevalent helminth Ascaris lumbricoides (18.98\%) was in agreement with the previous study done in Nepal (Shrestha and Maharjan, 2013). Hymenolepis nana occurs worldwide, reportedly with highest prevalence rates under the condition of poor sanitation and overcrowding but this study showed a lower prevalence which matches with other studies done in Nepal (Malla et al., 2004; Shrestha and Maharjan, 2013; Pradhan et al., 2014).

High prevalence among Dalits $(63.88 \%)$ appeared which was in agreement with the reports (Agrawal et al., 2012; Ishiyama et al., 2003). This could be due to low literacy rate, health ignorance or low socioeconomic status. There was the significant association between higher intestinal infection and those children, who did not take antiparasitic drugs did not use soap water after defecation and did not have water on the toilet. It means the children who were not following hygiene practices were more infected which is also depicted by other studies in Nepal (Shakya et al., 2006, Sherchand et al., 2010).

\section{Conclusion}

Parasitosis in children of Squatter community is still prevalent as major public health problems. This result concluded a poor hygiene and sanitary conditions, improper water supply and uneducated family. In order to prevent this infection, appropriate health education should be given to children and their parents concerning disease transmission, personal hygiene and safe drinking water. Efforts from the municipality to improve the quality of drinking water supply and the types of toilets being used will certainly lower the number of parasitic infections in such area.

\section{Acknowledgement}

The authors want to express a sincere gratitude to all the children and their parents of Squatter community of Dharan Municipality for providing stool samples, needed information and all the members of Sunsari Technical 
College for providing laboratory facilities needed for the study.

\section{References}

Agrawal PK, Rai SK, Khanal LK, Ghimire G, Banjara MR, Singh A (2012) Intestinal Parasites among Patients Attending Nepal Medical College Teaching Hospital, Kathmandu, Nepal. Nepal Med Coll J. 14(2): 80-83.

Bogitsh BJ, Carter CE and Oeltmann TN (2013) Human parasitology: Academic Press.

Chandrashekhar TS, Joshi HS, Gurung M, Subba SH, Rana MS and Shivananda PG (2005) Prevalence and distribution of intestinal parasitic infestations among school children in Kaski District, Western Nepal. Journal of Medicine and Biomedical Research 4(1): 78-82.

Department of Health Services; Ministry of Health and Population, Nepal. Annual Report. 2010/11.

Gyawali N, Amatya R and Nepal PH (2009) Intestinal parasitosis in school going children of Dharan Municipality. Nepal. Trop Gastroenterol. 30(3): 145-147.

IFAD (2010). Country Technical Notes on Indigenous Peoples' Issues: Nepal. International Fund for Agricultural Development, Rome Italy.

Ishiyama S, Rai SK, Ono K and Uga S (2003). A small-scale study on intestinal parasitosis in a remote village in Nepal. Nepal Med College J. 5: 28-30

Jaiswal S, Pant DR, Tiwari BR, Sah JP, Bhandari R and Upadhyaya S (2013) Prevalence of Intestinal Parasite among School Children of Bharatpokhari VDC, Kaski, Nepal. British Microbiology Research Journal. 4(9: 100712. DOI: $10.9734 / \mathrm{BMRJ} / 2014 / 8367$

Khanal LK, Choudhury DR, Rai SK, Sapkota J, Barakoti A, Amatya R and Hada S (2011) Prevalence of intestinal worm infestations among school children in Kathmandu, Nepal. Nepal Med Coll J. 13 (4): b272-274.

Latham MC (1997) Human Nutrition in the Developing World. Vol 29: Food \& Agriculture Org.

Magar DT, Rai SK, Lekhak B and Rai KR (2011) Study of parasitic infection among children of Sukumbasi Basti in Kathmandu valley. Nepal Med Coll J. 13(1): 7-10.
Malla B, Sherchand JB, Ghimire P and Gauchan P (2008) Prevalence of intestinal parasitosis infection in malnutrition among children in rural community of Sarlahi, Nepal. Journal of Nepal Health Research Council. 2 1-4.

Mathers C, Fat DM and Boerma JT (2008) The global burden of disease: 2004 update: World Health Organization. DOI: 10.1016/b978-012373960-5.00335-x

Mukhiya RK, Rai SK, Karki AB and Prajapati A (2012) Intestinal protozoan parasitic infection among school children. Journal of Nepal Health Research Council. 10 (22):204-7

Nepal Survey Division, Government of Nepal, Ministry of Land Reform and Management, Survey Department. Sukumbasi Ayog 2000.

Pooja RG, Rai KR, Mukhiya RK, Tamang Y, Gurung P, et al. (2014) Prevalence of Intestinal Parasites and Associated Risk Factors among School Children of Kalaiya in Bara District, Nepal. JSM Microbiology. 2(1): 1009.

Shakya B, Rai SK, Rai G, Shrestha A and Singh A (2006) Study on Intestinal Infections by Parasite and some Bacteria Among Elderly People of Kathmandu Valley. Nepal Med Coll J. 8(4): 243-247.

Sherchand SP, Joshi DR, Adhikari N, Gurung K, Pant K, Pun R, Shrestha D and Parajuli K (2010) Intestinal Parasitosis among School going Children. JHAS. 1(1): 12-15.

Shrestha A, Narayan KC and Sharma R (2012) Prevalence of Intestinal Parasitosis among School Children in Baglung District of Western Nepal. Kathmandu Univ. Med. J 37(1): 3-6. DOI: 10.3126/kumj.v10i1.6904

Shrestha B (2003) Intestinal parasitic infestation in healthy school children of Lalitpur district. Journal of Nepal Medical Association. 41(141): 266-270.

Shrestha R and Maharjan M (2013) Prevalence of Intestinal Helminth Parasites among School Children of Bhaktapur District, Nepal. Nepalese Journal of Zoology. 1(1): 48-59.

WHO (2013). Intestinal Parasites: Burdens and Trends. Available from: https://apps.who.int/ctd/intpara/burdens.htm.

W HO (2014) Fact Sheets, Intestinal worms. 